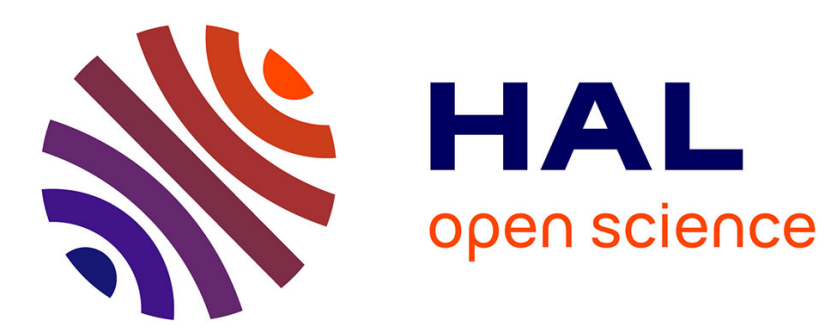

\title{
Field-usable sharpless wafers for Josephson effect devices at millimeter waves
}

J. Edrich, J.D. Cupp, D.G. Mcdonald

\section{To cite this version:}

J. Edrich, J.D. Cupp, D.G. Mcdonald. Field-usable sharpless wafers for Josephson effect devices at millimeter waves. Revue de Physique Appliquée, 1974, 9 (1), pp.195-197. 10.1051/rphysap:0197400901019500 . jpa-00243737

\section{HAL Id: jpa-00243737 https://hal.science/jpa-00243737}

Submitted on 1 Jan 1974

HAL is a multi-disciplinary open access archive for the deposit and dissemination of scientific research documents, whether they are published or not. The documents may come from teaching and research institutions in France or abroad, or from public or private research centers.
L'archive ouverte pluridisciplinaire HAL, est destinée au dépôt et à la diffusion de documents scientifiques de niveau recherche, publiés ou non, émanant des établissements d'enseignement et de recherche français ou étrangers, des laboratoires publics ou privés. 


\title{
FIELD-USABLE SHARPLESS WAFERS FOR JOSEPHSON EFFECT DEVICES AT MILLIMETER WAVES (*)
}

\section{J. EDRICH} Department of Electrical Engineering and Denver Research Institute
University of Denver, Denver, Colorado 80210, USA

\section{J. D. CUPP and D. G. McDONALD}

Cryogenics Division, National Bureau of Standards Boulder, Colorado 80302, USA

\begin{abstract}
Résumé. - On montre comment des «Sharpless wafers " modifiés peuvent être utilisés pour des dispositifs Josephson à contact à pointe, tels que détecteurs, changeurs de fréquence, oscillateurs et amplificateurs paramétriques. Les premiers résultats expérimentaux montrent que ces dispositifs sont robustes, peuvent être réglés à la température ambiante et être recyclés thermiquement sans dommage.

Abstract. - It is shown how modified Sharpless wafers can be used for point contact Josephson effect detectors, converters, oscillators and parametric amplifiers. First experimental data indicate that this method results in devices that are rugged, can be permanently adjusted at room temperature and can be cycled in temperature.
\end{abstract}

1. Introduction. - Point contact devices based on the Josephson effect can exhibit small stray reactances. Another important characteristic of these junctions is their relatively large resistance. Therefore, they are particularly attractive for detection, conversion, harmonic generation, oscillation and parametric amplification from low millimeter wave up to infrared frequencies [1]-[5]. However, these devices generally exhibit the following undesirable characteristics: (a) They cannot be temperature cycled without readjustment of the point, $(b)$ they have to be adjusted when cooled, $(c)$ their application is limited because of their sensitivity to shock and vibrations. The design described in this paper overcomes the above-mentioned disadvantages of conventional point contact devices by using a modified Sharpless wafer [6].

2. Design considerations. - The Sharpless wafer described contains the point contact junction and some of the biasing and rf filtering circuits. Figure 1 shows a schematic crossection of such a wafer diode which can be used as detector, mixer, converter, harmonic generator, oscillator or parametric amplifier. Similar designs have successfully been employed in cryogenically cooled parametric amplifiers up to $46 \mathrm{GHz}$ [7].

The point contact is located in the reduced height

(*) This work was supported by National Science Foundation Grant GP-38737.

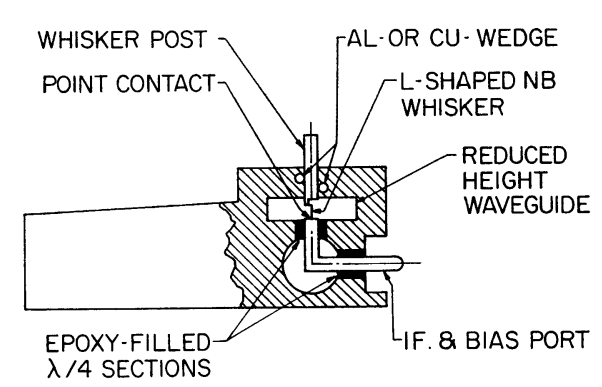
Fig. 1. - Cutaway view of Josephson effect mixer in Sharpless
wafer.

waveguide section of the wafer. It consists of a chemically sharpened $0.05 \mathrm{~mm}$ thick niobium whisker which is contacting the flat, polished end of a $0.75 \mathrm{~mm}$ thick niobium pin. The whisker has a 90 degree bend close to the area where it is spot-welded to a $0.75 \mathrm{~mm}$ thick niobium post. This method allows the use of a very thin and short whisker, and, yet, results in a rugged and - at the same time - elastic structure.

A filter consisting of three coaxial transmission line sections is used to bias the junction and to extract the if signal in the case of a mixer. These sections have an electrical length

$$
l=n \frac{\lambda}{4} \text { with } n=1,3,5, \ldots
$$

at the signal wavelength $\lambda$ of the mixer. The characteristic impedance of these sections is low $\left(Z_{\mathrm{L}} \leqslant 20 \Omega\right)$ in the epoxied areas and high $\left(Z_{\mathbf{H}} \geqslant 100 \Omega\right)$ in the 
airfilled, circular section. This results at the signal frequency in a sufficiently low impedance

$$
Z=\frac{Z_{\mathrm{L}}^{4}}{Z_{\mathbf{H}}^{2} Z_{0}} \leqslant 0.32 \Omega
$$

measured from the point contact away into the filter ; the filter is assumed to be terminated with the input impedance $Z_{0} \sim 50 \Omega$ of an if amplifier which can be a mixer, a parametric amplifier or a cooled transistor amplifier. This way a rejection of the rf from the bias and if port is obtained while allowing a reasonable match of the if port. If more than one $\mathrm{rf}$ frequency has to be rejected - like the signal-, idling- and pump-frequencies of a parametric amplifier - then one can still achieve good rf rejection by increasing the $Z_{\mathbf{H}} / Z_{\mathbf{L}}$ ratio and - if necessary - deviating from the simple case of $\lambda / 4$-long sections. This has practically been demonstrated in degenerate parametric amplifiers for millimeter waves [7].

3. Experimental results and discussion. - Figure 2 shows the photograph of such a Josephson effect mixer wafer for the 40 to $60 \mathrm{GHz}$ frequency range. The

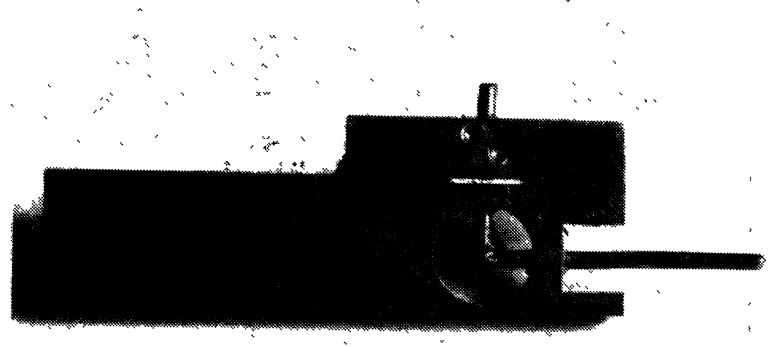

FIG. 2. - Photograph of a Josephson effect point contact mixer in Sharpless wafer for the 40 to $60 \mathrm{GHz}$ frequency range.

straight portion of the niobium whisker and its tapered end are clearly visible in the reduced height waveguide section. The 90 degree bend is almost completely covered by the through hole for the whisker post. Figure 3 shows an enlarged view of the area close to the point contact.

A special whisker driver jig is used to adjust the whisker at room temperature. This jig is shown in the photograph in figure 4. The Josephson mixer wafer is mounted on a block in the middle portion of the picture. A shielded lead is attached to the bias port of the wafer. One turn of the large wheel on the right-hand side of the differential jig corresponds to a movement of the driving bolt by about $25 \mu \mathrm{m}$.

One of the advantages of this design is that the wafer can be assembled and the permanent contact be adjusted at room temperature using the described whisker driver jig. The mentioned $L$ shape of the whisker and the highly differential whisker driver result in a very reproducible contact with low resistance (1 $\Omega<R_{\mathrm{D}}<60 \Omega$ ) without excessive flattening of the whisker point $(D<5 \mu \mathrm{m})$. Some of the test junctions were made in an atmosphere of helium gas and afterwards sealed by a small drop of epoxy which formed a meniscus of less than $40 \mu \mathrm{m}$ height.

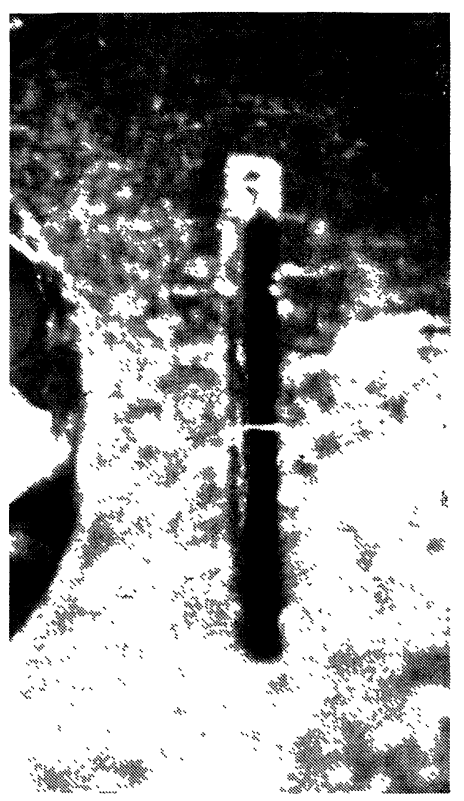

FIG. 3. - Close-up view of the waveguide - mounted and epoxy-sealed Josephson point contact junction.

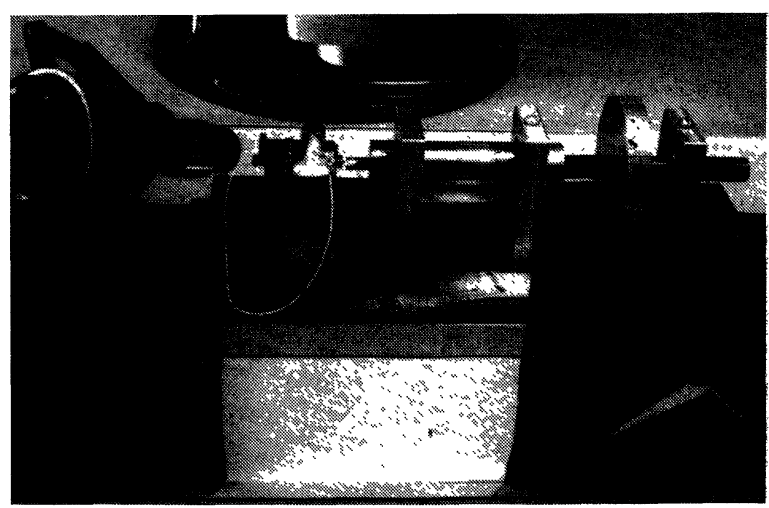

FIG. 4. - Photograph of the differential whisker driver jig used to adjust the point contact at room temperature.

Both types of junctions - epoxy sealed or unsealed - yielded mechanically stable contacts that could not be destroyed by dropping of the completed wafers or by repeated temperature cycling between room temperature and a temperature of $4.2 \mathrm{~K}$. Preliminary long-time stability tests extending up to $30 \mathrm{~h}$ have not shown noticeable degradation of the contacts.

Cooling of these junctions to $4.2 \mathrm{~K}$ yielded reproducible and stable $I-V$ characteristics with super- 
currents ranging from $0.2 \mathrm{~mA}$ to $0.4 \mathrm{~mA}$ and a differential resistance $R_{D}^{\prime}$ from 0.4 to $15 \Omega$ in the normal conduction region.

These results indicate that it is possible to construct rugged and field-usable point contact junctions for Josephson effect applications for frequencies up to at least $300 \mathrm{GHz}$ using a modified Sharpless wafer design.

\section{References}

[1] SOLymar, L., Superconductive Tunnelling and Applications (Wiley Interscience, New York) 1972, p. 256.

[2] McDonald, D. G., Petersen, F. R., Cupp, J. D., Danielson, B. L. and Johnson, E. G., Revue Phys. Appl. 9 (1974) 273.

[3] Kanter, H., Dig. of Int. Conf. on Detection and Emission of Electromagnetic Radiation with Josephson Junctions (1973), paper VIII 5 and J. Physique, Jan. 1974.
[4] Taur, Y., Claassen, J. H. and Richards, P. L., Revue Phys. Appl. 9 (1974) 263.

[5] Elstey, R. K. and Sievers, A. J., Revue Phys. Appl. 9 (1974) 295.

[6] Sharpless, M. W., Bell Syst. Tech. J. 35 (1956) 1385.

[7] Edrich, J., P-GMTT IEEE Int. Microw. Symp. (1973) 80 and IEEE Trans. on MTT 21 (Dec. 1973). 